\title{
Shackle on time, uncertainty and process
}

\author{
Article
}

Accepted Version

Latsis, J. (2015) Shackle on time, uncertainty and process. Cambridge Journal of Economics, 39 (4). pp. 1149-1165. ISSN 1464-3545 doi: https://doi.org/10.1093/cje/bev031 Available at https://centaur.reading.ac.uk/40237/

It is advisable to refer to the publisher's version if you intend to cite from the work. See Guidance on citing.

To link to this article DOI: http://dx.doi.org/10.1093/cje/bev031

Publisher: Oxford University Press

All outputs in CentAUR are protected by Intellectual Property Rights law, including copyright law. Copyright and IPR is retained by the creators or other copyright holders. Terms and conditions for use of this material are defined in the End User Agreement.

\section{www.reading.ac.uk/centaur}

\section{CentAUR}

Central Archive at the University of Reading

Reading's research outputs online 


\section{Shackle on Time, Uncertainty and Process}

\section{Introduction}

Contributions to heterodox economics have long made use of the idea of 'process' to provide an analytical lens through which to understand the history of economic thought (e.g. Nelson 2003), and as an essential element of the alternative ontology that the different heterodox schools of thought could be said to share (Lawson 2006; 2012). Institutionalist, feminist, post Keynesian or Austrian approaches are described as 'processual', or as relying on the ontological assumption that the social world is 'dynamic' and 'exists in a continual state of becoming' (Lawson 2006: 495). This description of what is claimed to be a unifying characteristic of the heterodoxy is readily connected to evolutionary or old institutionalist theories. Indeed, it is an attractive and intuitively plausible descriptor for the emphasis on dynamic change that these approaches share. However, part of the appeal of process theory in the heterodox literature comes from its highly abstract and general formulation and further conceptual work is necessary to enable a more consistent, though perhaps more restricted, usage of the term.

This paper is intended both as a contribution to the conceptual work on process in economic thought, and as an attempt to connect a non-institutionalist, non-evolutionary thinker to it. As such, the paper has two purposes:

1. To delineate a broad, philosophically grounded conception of what an economic process theory (EPT) is.

2. To locate the contributions of George Shackle within this broad conception of EPT.

My primary objective is to provide a framework that can be used by others to study process theories within economics and to apply it to a difficult case at the boundary of what might previously have been considered processual economics. A secondary ambition is to draw out the originality and significance of Shackle's approach with a particular emphasis on areas where he offers a different perspective to process conceptions developed within other traditions such as institutional and evolutionary economics. Reading Shackle as an economic process theorist in my sense is, I will argue, a resource for those wishing to defend his ideas against a number of critical arguments.

The paper is divided into three parts. Part I sketches the history of Western process thinking and summarises its key characteristics in order to distil four key desiderata for an EPT from them. Part II provides a brief description of Shackle's 
economics, with a special emphasis on his conceptions of time and uncertainty. I claim that Shackle's treatment of these two key concepts marks him out as a significant modern proponent of EPT. Part III describes the reception of Shackle's work, the allegations of analytical nihilism and the perceived problem of social order. I claim that these critiques lose much of their force when his contribution is understood as a process theory.

\section{Part I}

\section{Process Philosophy}

Philosophical research - from which many of the processual ideas adopted by heterodox economists originate - is as plausible place as any to seek a more precise conception of what a process theory is, and that is what I now propose to do.

Process philosophy is concerned with the study of the nature of being and thus is considered to be part of the broader sub-discipline of ontology. It can be contrasted with, and is often constructed in direct opposition to, 'substance metaphysics' - the mainstream view of ontology in Western philosophy - which claims that the 'stuff' of being is internally undifferentiated and static. According to this view, a singular unchanging substance undergirds our experience of the world and the task of ontology is to investigate it. Process philosophy's main objective, then, is to undermine the substance view and its attendant conception of entities, and to construct an alternative ontology that takes process as its basic building block.

Western process thought is usually traced to the writings of Heraclitus and Leibniz but most modern variants can be connected to at least one of two philosophical traditions: continental philosophy and American pragmatism. European process thought arose out of German idealism, in particular Fichte, Hegel and Schelling's criticism of Kant. It assumes that philosophical enquiry can be speculative in the sense that the process of reality follows principles that are open to philosophical (rather than empirical) investigation. Arising, as it did, from idealism, it is no surprise that this approach privileges the study of the process of human cognition with a focus on the subjective experiences of the thinker. Most importantly, this continental tradition does not draw a close connection between process philosophy and the study of concrete processes such as might be found in the natural and social sciences. This gulf between ontological reflection and scientific practice was not reproduced in the work of Anglo-Saxon process philosophers, many of whom started from similar premises. 
Hegel's ideas about process inspired a different tradition in the United States that grew out of the philosophical and social-psychological research of John Dewey and William James. Dewey's philosophical perspective has been the most influential within the social sciences ${ }^{1}$. He argued that the study of ontology does not involve projecting the individual mind out onto an unknown reality. Instead, the mind itself emerges from the continuous flow of interactions between organisms and their environment. Dewey's most basic ontological claim is that reality is made up of events rather than substances. These events are episodic in the sense of having a unique qualitative feel. However they are also part of broader structured patterns that are the target of scientific study. According to Dewey, events (possessing this dual character) are also conditioned by the nature of ontological enquiry, which is itself a social, linguistic activity carried out collectively. Within pragmatism, social interaction is not a mystery to be explained, but a constitutive component of the mind and a crucial target of both scientific and philosophical inquiry. This is significant, because it placed the ontology of process in the public realm, thus making it amenable to (indirect) empirical study by sociologists and psychologists (e.g. Mead 1934). This empirical turn seems to be the key to understanding much of modern process thought in the Anglo-Saxon tradition, which has moved away from speculative pursuits and sought closer connections with the natural and social sciences.

Arguing from the within the empiricist, analytical tradition of Western philosophy, which is dominated by substance metaphysics, Nicholas Rescher (1996, 2000) has elaborated and defended a comprehensive process philosophy. His approach incorporates ideas from both historical traditions, whilst maintaining intellectual proximity and an open dialogue with mainstream philosophy of science. Like the pragmatists, Rescher is concerned to relate the ontological insights of process philosophy to empirical phenomena, and in particular to the natural sciences. Both the stated ambitions and the influence of Rescher's contribution within the philosophical literature, suggest that his work can provide a good foundation for extending a systematic process philosophy into economics. Rescher's perspective is best understood by quoting him at length:

'...process philosophy" may be understood as a doctrine committed to, or at any rate inclined toward, certain basic propositions:

(1) Time and change are among the principal categories of metaphysical understanding.

\footnotetext{
${ }^{1}$ Institutional economics, in particular, owes a significant intellectual debt to Dewey.
} 
(2) Process is a principal category of ontological description.

(3) Processes are more fundamental, or at any rate not less fundamental, than things for the purposes of ontological theory.

(4) Several if not all of the major elements of the ontological repertoire (God, natureas-a whole, persons, material substances) are best understood in process linked terms.

(5) Contingency, emergence, novelty, and creativity are among the fundamental categories of metaphysical understanding.

A process philosopher, accordingly, is someone for whom temporality, activity, and change - of alteration, striving, passage, and novelty emergence - are the cardinal factors for our understanding of the real'. (Rescher 2000: 5).

Of course, this definition depends crucially on what we understand a process to be - a potentially thorny problem. Rescher defines a process as 'an actual or possible occurrence that consists of an integrated series of connected developments unfolding in programmatic coordination: an orchestrated series of occurrences that are systematically linked to one another either causally or functionally' (Rescher 2000: 22). He articulates this further by proposing three distinctive features or 'pivotal facts' about process:

1. A process is a complex of distinct phases.

2. A process has a temporal dimension (time is essential to it).

3. A process has a generic structure in virtue of which any concrete process is shaped or formatted.

In summary, despite historical divergences and differing views on the connection between philosophy and empirical research, process philosophy can be seen as a coherent ontological perspective (at least at an abstract, meta-theoretical level). Rescher's framework provides a plausible general characterisation of what a process is and criteria for identifying a philosophical process theory, which are specific enough to pick out a range of relevant historical and contemporary philosophical positions, but broad enough to encompass diversity ${ }^{2}$. It is my contention that this basic framework can be usefully extended in order to develop a better understanding of EPT.

\footnotetext{
${ }^{2}$ Several of Rescher's key technical concepts are open to multiple interpretations and may be used differently in different strands of the literature. Emergence is one such concept that I shall return to explicitly in Part II.
} 


\section{Desiderata for an Economic Process Theory}

It is clear that Rescher's definition of the scope of process philosophy is directed at a philosophical audience. More specifically, points 3 and 4 are not central elements of the social scientific project. It is not generally deemed to be the job of economists to determine which ontological categories are 'most fundamental' (Proposition 3) in any general sense of the phrase. Similarly, the classical philosophical puzzles relating to God's existence, personal identity and materialism (Proposition 4), though they may have an impact on the practice of economics, are not the primary focus of the discipline. This leaves propositions 1, 2 and 5, from which we can construct a tentative list of desiderata for an EPT.

Following Rescher, I have already stipulated that processes must have both a phased structure and a temporal dimension, which implies that both the passage of time and the recognition of change between the different phases (Proposition 1) must be basic ontological categories within an EPT. That process is an analytical category of ontological description (Proposition 2 ) is an obvious criterion to adopt in the philosophical literature, but it may place the bar too high when attempting to understand contributions to economics. Very few economic theorists make their ontological assumptions explicit in a way that would allow them to be easily identified - it is usually up to methodologists and historians of thought to tease out the implicit message ${ }^{3}$. Proposition (5), which emphasises the ontological centrality of the categories of contingency, emergence, novelty, and creativity is much more apt for the analysis of economic theory, since these categories are more likely to be explicitly put to use in theory construction rather than the more abstract conception of process.

Selectively recombining Rescher's ideas, we arrive at the following list of four desiderata that we would expect an EPT to possess:

1. An EPT must recognise the ontological and explanatory importance of the passage of time.

2. An EPT must recognise the ontological and explanatory importance of the difference between successive and different phases in a temporal process.

3. Though it may not be explicitly discussed, the notion of process should be a basic (though perhaps implicit) presupposition of an EPT.

4. An EPT should be able to accommodate the ontological categories of contingency, emergence, novelty and creativity whilst maintaining its principal explanatory ambition.

\footnotetext{
${ }^{3}$ This type of work is a growing part of the methodology and history of though literature which has been referred to as scientific ontology or internal metaphysics by some commentators (Lawson 2014).
} 
These elements will allow us to identify the common themes and characteristics that unify economic process theorists, whilst leaving space for both theoretical diversity and the influence of schools of thought on the history of economic ideas.

The second part of this paper will extend my analysis to an author who is notoriously difficult to categorise: George Shackle. I have deliberately chosen Shackle as a focus because his contribution stands out both for its originality and for the difficulty that interpreters of his work have faced in attempting to classify him within the canon of one or other heterodox school of thought. My contention will be that Shackle is an economic process theorist, which explains his affinities with post Keynesianism, Austrian Economics and Institutionalism and his relative neglect in both heterodox and mainstream methodological debates. This will allow me to show (in the third part of the paper) how treating Shackle's approach as an EPT suggests new responses to two seemingly powerful critiques of his work.

\section{Part II}

\section{Shackle's Contribution}

Shackle is an unusual figure in the history of $20^{\text {th }}$ century economics. He was a talented and prolific writer who developed a heterodox approach to decision making under uncertainty informed by psychology and philosophy. He was a student of Hayek and a follower of Keynes, who was difficult to classify as either post Keynesian, or Austrian, though he had affinities with both schools of thought. He was mainly concerned with macroeconomic problems, but his research focussed on the psychology of individual choice under uncertainty in order to solve them. And he was sophisticated philosophical thinker who has had limited impact on the philosophy of economics. These tensions have been duly noted by historians of economic thought, who have recognised Shackle's contribution to a variety of intellectual debates whilst noting his unusual status within the profession (Harcourt 1981; Harcourt and Sardoni 2000).

The first part of Shackle's career culminated in research (Shackle 1949, 1955, 1961) that responded to a question posed by Keynes in his analysis of investment decisions: how do we make 'risky' decisions and 'save face as rational men'? For Shackle, the key to understanding such decisions was the recognition that they were based on expectation rather than established fact, and that theorising about the future was qualitatively different from describing past occurrences. Following Frank Knight, Shackle rejected the concept of probabilistic risk advocated by mainstream theorists and outlined a theory of investment decision that eschewed numerical probabilities in favour of a subjectivist, psychologically grounded explanation. 
Stripped of its technical form, his theory contains three basic elements. First Shackle claims that an investor must simplify a choice between alternative ventures by determining two focus outcomes (focus gain and focus loss): one representing what he 'stands to gain' and the other representing what he 'stands to lose'. These are judged on the basis of their desirability, which can be measured. However, the desirability of an outcome does not affect the likelihood of its occurrence, hence Shackle introduces the dual notions of possibility and surprise. His concept of 'possibleness' is a second subjective variable, based on the specific experience and intuitions of the investor, it determines the range of outcomes that are considered in the decision making procedure. However, possibleness is categorical: an outcome is either deemed to be possible or not. Shackle therefore proposes the subjective feeling of 'potential surprise' as a proxy measure that allows investors to decide between competing ventures at the moment of decision. He sums his position up as follows:

"The act of decision is a fusing of judgments of different kinds, and these judgments in effect are made all at once in that moment and have their mutually relevant existence in that moment. The chooser of action wishes to fix upon the best and worst imagined outcome of each action that are possible enough: the best that is possible enough to be worth hoping for, and the worst that is too possible to be dismissed." (Shackle 1988: 5)

It is important to note that, despite the use of deductive modelling techniques and an evident desire to formulate the theory in terms amenable to a dialogue with the mainstream, Shackle's position was perceived to be radical from the start. Its radicalism is emphasised both by his rejection of probabilistic reasoning and by his emphasis on understanding the processes underlying decision making rather than simply focussing on predicting outcomes (Watkins 1955: 72).

Shackle's later research is more directly engaged with working on the philosophical themes that were implicit in his contribution to decision theory. An important part of this work involved a discussion of 'Keynesian Kaleidics' (Shackle 1974; 1983), which drew on an original reading of Keynes through his 1937 QJE article and Hugh Townshend's interpretation of the General Theory. Much of what Shackle said in the seventies about the importance of radical uncertainty and the instability of expectations in Keynes has gained wide acceptance amongst heterodox (and particularly post Keynesian) economists and I shall therefore not develop it here.

More controversially, however, Shackle strayed into overtly philosophical territory in his analysis of the nature of time, imagination and choice (Shackle 1959; 1972; 1988). Writing in the British Journal for the Philosophy of Science, Shackle 
contrasted the implicit views of time deployed by mathematicians or historians with the individual, experiential perception of time. According to Shackle, the mathematical conception of time involves a necessary compression of the experience of the passage of time, which is part of representing a physical process through equations. Taking the example of the movement of particles in classical dynamics, he shows that, in order to be able to interpret differential equations as representing a physical process occurring over time, the mathematician must see the process as a snapshot. He must cast himself as an observer of this snapshot located outside the flow of events that characterises the real process being described. However, there is an alternative, phenomenological, view of time, which sees it as a subjective experience:

'From this inside view which each of us has in the very act of living, the time of our actual psychic experience is but a moment, utterly solitary in its isolation from all other moments. It is what I would like to call the solitary present or the moment-inbeing... Time from the inside is the time in which we think, time from the outside is the time about which we think.' (Shackle 1958: 286)

According to Shackle, therefore the passage of time is thus both an external movement along a calendar and an internal movement from one moment to another.

But, Shackle's theory also accommodates the human ability to imagine the future or 'create images unaided by outside stimulus, and to label them with dates other than the actual date at which such images are created' (1958: 288). This type of imagining is central to Shackle's economic theory, in the sense that it is from the operation of the (constrained) imagination that an individual forms their subjective image of the future. The latter is made up of forward-looking expectations and anticipations. Expectations of alternative possible futures are constrained by the agents' beliefs about the natural order and human abilities. Anticipations are similarly constrained, but are additionally limited by the imagination of a specific set of outcomes in those future states, to which the individual has some sort of commitment (Shackle 1958: 288-289).

Shackle's conception of choice as origination builds on these two ideas since choices are always made by imaginative agents at specific moments employing the inside view of time:

'A non-determinist view of history requires us to suppose that a choice can be in some respects exempt from governance by antecedent thought or contemporary circumstance, that a choice can be in some respects an uncaused cause.' (Shackle 1988: 2) 
His commitment to the reality of such choices is not based on an a priori assumption of human freedom (though it is open to those who would make such an assumption). Instead, every choice shifts the bounds of possibility by committing the chooser to one imagined sequel out of many alternatives. Since there is no way of putting an objective limit on those imagined sequels, nor a rational selection mechanism within the bounds of those that are subjectively deemed to be possible, choices are by definition unpredictable. Thus for Shackle, choices are creative acts that have the potential to add novelty to the chooser's environment: they make the future 'unknowable', or in more conventional terms uncertain.

\section{Shackle as an Economic Process Theorist}

It remains to draw the links between these basic elements of Shackle's conception of economic activity and my proposed desiderata for an Economic Process Theory. Since Shackle did not employ an evolutionary framework, or engage in any substantive way with the (old) institutionalist literature, he lacks clear processual credentials. The links between institutionalism, pragmatism and evolutionary thinking are both explicit in the original sources and well articulated in the secondary literature. Conversely, there have been very few attempts to link Shackle's work to processual themes in the methodological literature, with a few notable exceptions (Lachmann 1976, Parsons 1993; Runde 1997; Hodgson 2000; Augier 2001) ${ }^{4}$.

Reintroducing my list of four desiderata will show that - given a more precise interpretation of what an EPT is - Shackle can be seen as defending a processual perspective. My first claim is that an EPT must recognise the ontological and explanatory importance of the passage of time. Shackle's detailed philosophical reflection on the nature of time starting in 1954 and ranging through to work collected and edited by Frowen in 1988, towards the end of his life, provides ample evidence of the centrality of the concept in his corpus. To my knowledge, no other economist has published an article on the nature of time in a leading philosophy journal. Apart from his aforementioned critique of the mathematical conception of compressed time as employed by economists, Shackle came to defend an ontology of time that saw its essence as something 'whose existence involves its continuous movement and continuous evolution' (Shackle 1958: 14). And as I have already noted, it would not be possible to make sense of his theory of imagination and

\footnotetext{
${ }^{4}$ An obvious strategy would be to trace concrete processual credentials through references to process philosophy within Shackle's work. Unfortunately, this strategy is hampered by the paucity of citations in his publications. One co-edited volume (Carter et al. 1954) does contain several responses to Shackle's work by philosophers. John Watkins (who contributed to the volume and reviewed him favourably in 1955), W.B. Gallie and Daniel O'Connor were all analytic philosophers working within the dominant paradigm. There is little evidence of their influence on Shackle's philosophical development within this volume, or indeed elsewhere.
} 
choice without these ontological assumptions (see also Augier 2001: 197-198) ${ }^{5}$. Thus, to the extent that Shackle's theory of decision-making is intended as an explanation of the investment decision and as a basis for a realistic theory of entrepreneurial behaviour, the idea of the passage of time has clear explanatory cachet.

Secondly, I proposed that an EPT must recognise the ontological and explanatory importance of the difference between successive and different phases in a temporal process. This idea is closely linked to the first, though not identical. The best way to show the importance of this element of temporality for Shackle is to consider his critique of general equilibrium. Even though mainstream economists can make reference to the passage of time and refer to successive phases (for example between periods or between the long and the short run), this is only a superficial appearance. Shackle argues that modelling general equilibrium requires the pre-reconciliation of all choices, which in turns requires those choices to be simultaneous $^{6}$. The whole system therefore leaves out the phase-like structure of temporal experience to what Shackle considered to be disastrous effect:

"The expressions an action, a course of action, a plan, an enterprise, a policy, are all in varying degrees synonymous. Some of them distinctly and obviously imply the occupation of a stretch of the calendar. But it is the unity or coherence, the organicity of the action or the plan that matters. Need we be concerned at having to suppose the 'successive' parts of the action or the plan to be telescoped? Does the dimension of lapse of time matter? The timeless system of choices must ignore the need for lapse of time. Is there something about the time-squeezed economy that need worry us?' (Shackle 1988: 11).

According to Shackle, the answer to this question is a resounding 'yes'. What is missing from the time squeezed economy is real choice. Real choices are discrete, or as Shackle likes to call them 'quantum shifts', which clearly differentiate between one phase and the next.

My third desideratum was that the notion of process should be a basic, though perhaps implicit, presupposition of the theory. Here the lack of an overarching evolutionary framework as would be found in, say, the work of Thorstein Veblen, prevents a straightforward answer. Nevertheless, there is ample

\footnotetext{
${ }^{5}$ Several commentators have hinted at a more direct and explicit connection between Shackle's treatment of time and process philosophy through the work of Henri Bergson (Ackerman 1958; Lachmann 1976, Ford 1993). Bergson was known to have influenced both Ludwig von Mises and Joseph Schumpeter, though Shackle does not cite him and denied any intellectual influence.

${ }^{6}$ Contemporary economists attacked general equilibrium on the basis of a catalogue of analytical shortcomings (e.g. Kaldor 1972; 1986), but none of them took quite as radical a line of critique as Shackle.
} 
evidence to suggest that the notion of the economy as an unfolding process rather than a static object is driving Shackle's analysis. Remember that a process involves at least three elements: distinct phases, a temporal dimension and a generic structure in virtue of which any concrete process is shaped or formatted. The first two elements are discussed in detail above, whilst the notion of generic structure is developed in Shackle's later work.

The word 'process' does not appear in the subject indices of Shackle's major philosophically inspired books (Shackle 1972; 1988), but processual themes are central to his argument. In particular, the extended discussion of diachronicity in Epistemics and Economics clearly demonstrates his abandonment of substance metaphysics in favour of a processual ontology. The presence of a generic structure within the processes he describes, Shackle argues, is presupposed by the success of our practical and scientific endeavours. More specifically, in the context of a discussion of how we can accumulate knowledge in and of a dynamic system, Shackle says:

'Theory in many disciplines is of course the study of temporal sequence, the study of transformations. The elemental basis of systematic knowledge by experience is that things of certain kinds happen in a fixed configuration which can be described only by saying that two specified phenomena were concomitant, or else that they were sequential. Induction may be insecurely based in logic, but it is the means of our learning to cope with practical life.' (1972: 285)

He goes on to define explanation in science as the ex-post discovery of what he calls 'traces' that connect unexpected present outcomes to a generic structure that shaped the present but was either poorly identified or unidentified in the past. He links this conception of explanation to our ability to make conditional scientific predictions and to produce practically useful technology. This account of generic structure is only superficially hampered_by Shackle's radical subjectivism: he speaks of traces because his philosophical framework lacks the tools to describe an unseen yet causally efficacious structure that underpins experience (see Runde 1997: 236240). Nevertheless his framework presupposes the existence of some such structure to account for the possibility of scientific knowledge and its accumulation over time.

My final proposal was that an EPT should be able to accommodate the categories of contingency, emergence, novelty and creativity. Novelty and creativity were key ideas for Shackle throughout his career and their possibility (indeed their inevitability) is at the root of his conception of choice and his kaleidic interpretation of the economic system. Augier (2001) has written extensively on this topic, whilst connecting Shackle's ideas to the phenomenological perspective of the sociologist Alfred Schutz, and Hodgson (2000: 55-57) makes similar claims on Shackle's behalf. 
Contingency is also unproblematic in the sense that the whole notion of prereconciliation of choices that Shackle argues against is an attempt to eliminate contingency from the analytical framework of economics. Indeed the notion of the contingent circumstances of the individual chooser is the key to understanding her mindscape and hence being able to reconstruct the subjective variables of possibleness and surprise that underpin Shackle's decision theory.

Emergence, on the other hand, poses more of an interpretive puzzle. The conventional notion of emergence as the appearance of a new (usually macroscopic) property from the interaction of the elements of a (usually microscopic) substratum organised in a particular way, is not explicitly articulated in Shackle's writings. Explicit talk of emergence in the work of economists (including evolutionary and institutionalist authors) is unusual, so the absence of an account is not surprising. Still, given the lack of textual evidence, it is difficult to claim that Shackle had any sort of clear commitment to the existence of emergent properties at the institutional or supra-individual level.

This gap should not be taken to suggest that emergent properties are completely absent from Shackle's framework. Geoff Hodgson (2000: 60-61) has speculated that the language of institutions as emergent properties could be compatible with Shackle's perspective and would have made his admiration of Keynes easier to understand in methodological terms. Jochen Runde is more critical when he notes the absence of an explicit account of structures (or generative mechanisms) in Shackle's theory. However, he too identifies that Shackle's account of the natural order underpinning subjective experience requires such structures. He does so by quoting another passage from the opening pages of Epistemics and Economics:

'The occurrence, over and over again of similar objects or events establishes a class of objects or events, a concept. Such concepts themselves can then form the building blocks of more complex and inclusive configurations. Science tells us what to count on, what to rely on. But in doing so it merely imitates and refines the process by which we build, each of us for himself, the homely technology of everyday living. The means of its doing so is the power of survival and reappearance of types of configuration.' (author's emphasis, Shackle 1972: 6-7)

The last sentence is key, because here Shackle clearly attributes the existence and success of the 'homely technology of everyday living' to the persistence of what he calls 'configurations': nothing other than the emergent structures of the natural world. 
It cannot be denied that Shackle's radical subjectivism and his systematic focus on the psychology of choosers favours an individualistic ontology where emergent properties are fixed at the level of what philosophers would call irreducible mental states ${ }^{7}$. This may be seen as problematic by those seeking to interpret him as a process theorist since for many process philosophers, the appearance of irreducible emergent properties from complex interactions in a physical or organic substratum is an important motivation for the adoption of process philosophy. Yet, we have already seen in the passage above that the emergence of natural mechanisms of this sort is consistent with Shackle's perspective. The problem facing Shackle is not the absence of emergent properties from his account, but the glaring absence of social emergent properties.

Here again, placing Shackle's account in the context of process philosophy is instructive. Whilst process philosophers agree about the centrality of the category of emergence, there is no widespread agreement on which emergent properties actually exist. The philosopher-psychologist Mark Bickhard, for example, seeks to anchor his sophisticated account of social life as process in an ontology of persons (individuals with irreducibly social characteristics), who construct the social realm first through what he calls 'situation conventions' and then through 'institutionalised conventions' (Bickhard, 2004). His passage from individuals with non-idealised cognitive and social capacities to conventions mirrors Shackle's reconstruction of Keynes's General Theory. The key point to take from Bickhard's discussion, however, is that recognising the thought and creativity of individuals as persons (rather than organic automata or machines) necessarily involves a commitment to emergence at least at the level of the individual agent (Bickhard 2004: 111-2). This last claim is entirely consistent with Shackle's approach to choice as origination, in which decisions cannot be predicted from antecedent conditions and must be treated as created ex-nihilo.

Thus, our discussion of Shackle's contribution to economic theory has highlighted the centrality of the concepts of time and uncertainty in his analytical framework and their implications for his theory of choice and the kaleidic nature of the economy as a whole. When juxtaposed with the four desiderata for an EPT, Shackle's work was found to be consistent with all of them, though his neglect of social emergent properties leads to some tension with more conventional process theories. The final part of this paper will address the lukewarm reception of Shackle's work amongst methodologists and heterodox economists more generally.

\footnotetext{
${ }^{7}$ It is implausible that Shackle adhered to the ontological, methodological and normative variants of methodological individualism. Yet all of these have, at some point, been proposed as centrally important to economics.
} 
My conclusion will be that many of the alleged failings of his approach are linked to the fact that his contribution is an EPT.

\section{Part III}

\section{Analytical nihilism and the impossibility of social order}

It would be an exaggeration to say that Shackle has been dismissed by recent heterodox research, but he certainly does not get the attention that some historians of thought think he deserves. Indeed, his early career was characterised by academic success and attention from leading figures from cognate disciplines (see e.g. Watkins 1955). However, as the mainstream of the discipline of economics moved away from his interests and his research turned to more abstract philosophical topics, the tide turned against him. His major work in economic philosophy (Shackle 1972) was reviewed in two leading philosophy journals, but both reviewers were scathing in their remarks and pointed to the ultimate futility of his intellectual project (Newman 1973; Boland 1974). There are two related strands to the critique of Shackle's work, both of which claim to identify serious limitations in it. The first and most common critical reaction has been to describe Shackle as 'analytically nihilistic' (Coddington, 1983: 61$)^{8}$. The second is deeper and more nuanced; it sees Shackle's emphasis on uncertainty and creativity as antithetical to any conception of social order and therefore inconsistent with the explanatory, predictive and policy ambitions of economics.

Analytical nihilism is a serious charge to bring against an economic theorist, since, taken at face value, it amounts to the claim that theorising is impossible and hence that his intellectual project is self-defeating. However, once Coddington's allegation of analytical nihilism is unpacked, it becomes clear that it cannot be sustained in Shackle's case. Rather than demonstrating that Shackle's project is selfdefeating, Coddington merely noted Shackle's recognition and articulation of intractable theoretical problems that pose definite limits on the scope of economic analysis. In this case, radical critique is misinterpreted as analytical nihilism because of its destructive effects on the corpus of incumbent theory. As Stephen Parsons (1993) convincingly explains, drawing on numerous examples from nihilistic philosophy and the history of economic thought, this is neither nihilistic nor unusual in economics.

\footnotetext{
${ }^{8}$ The allegation of nihlism was almost certainly aided by a misinterpretation of something Shackle said when discussing the later works of Keynes (Shackle 1983).
} 
However nihilism as a position in modern economic methodology can be reformulated in a more restricted manner. Warren Samuels has suggested that it consists of a commitment to five basic ideas: free will; subjectivism; the belief that human decisions partially construct social reality; radical uncertainty; and diffidence about policy recommendations (Samuels 1993: 237). This definition, which Samuels himself endorses, is clearly also applicable to Shackle's work. Rather than denying the possibility of theory, however, it denies the possibility of a certain type of theory and proposes the foundations of an alternative. Samuels' nihilism is only nihilistic in the sense that it rejects the received wisdom of the discipline from which it sprung it cannot be seen as a denial of the possibility of theory.

Why, then, did the allegation survive and even persist in the economic literature? Sociological factors may have played a role: accusing an intellectual opponent of nihilism is a quick and potentially effective way of dismissing his ideas and avoiding the need to respond to his critique. But this is merely speculation and it cannot explain both Shackle's and Samuels' flirtation with the nihilistic label. A more promising way of interpreting both the allegation of nihilism and the potential attraction of the label is to place it in the context of process theory.

The key to this idea is that the objectives of an EPT are fundamentally different from those of a substance metaphysics-inspired theory. First, the theoretical terms of an EPT refer to unstable targets, not settled entities, and they tend to be understood in terms of functional criteria rather than identity conditions. Second (as process philosophers have long argued), the language of Western science is poorly equipped to analyse processual phenomena. The dominance of the substance ideal during the period when our scientific vocabulary and concepts were developed created a powerful block to the development of process theories in science (Rescher 1996: 83-103).

Thus, the battle to establish an EPT is both an argument for the adoption of an alternative social ontology and an attempt to develop a new language for describing economic phenomena. The creation of a new jargon, however, immediately opens the inventor (in this case Shackle) to accusations of obfuscation and, potentially, of analytical nihilism. As one philosophical critic clearly demonstrates:

'Behind this [Shackle's theory] lies the plea to view all this in a dynamic setting, since akin to thinkers like Bergson, rational de-humanizing science must satisfy phenomena which, by nature, are always in process and transformation. A view of this order clearly constitutes a good antidote to much of the research which goes on in the social sciences today, However, it remains an unfortunate point that romantic 
inspiration alone will not improve our understanding of the many complexities of a dynamic economic society.' (Newman 1973: 412)

Here Shackle's contribution is dismissed as 'romantic inspiration' precisely because it does not accord with the reviewer's pre-conceived ideas of how a theory can bear empirical fruit in accordance with the Popperian framework that dominated the philosophy of economics at the time. The implication is clear: choosing an EPT over an impoverished mainstream theory is nevertheless irresponsible because it is destructive of the accumulation of scientific knowledge. Since the language and epistemic objectives of an EPT are different from the mainstream, the conclusion of analytical nihilism follows readily from this argument.

A second, related, reason why Shackle's work has been dismissed by some and ignored by others is his apparent lack of a systematic account of social order. There are at least two features of this critique which are worth considering separately. First, Shackle's commitment to radical subjectivism leaves him open to the perceived threat of solipsism. Second, his kaleidic conception of the economy eviscerates the possibility of rationally predicting future states of affairs and thus robs economics of its pretensions as a policy science.

Solipsism is the philosophical doctrine that only the existence of one's own mind can be established with any certainty because knowledge of a world beyond its limits is inherently dubitable and subject to philosophical challenge. If subjectivism describes the position that economics must always start from people's subjective interpretation of their situation, radical subjectivism can be defined as the further claim that subjectivism should be extended so that it 'embraces not just people's choice of means but also the creation of the goals they strive to achieve and the expectations that inform their choice of goals' (Lewis 2011: 188). Discussing radical subjectivism in the work of Ludwig Lachmann, Paul Lewis explains how the radicalism of this approach renders the very idea of coordinated expectations problematic and was thus interpreted as anti-theoretical by critics. If an individual economic agent cannot rationally calculate the probable future behaviour of his fellows, then he will not be able to form expectations of future states of affairs and will remain paralysed. Thus, in the hands of economists, the inability to extend secure knowledge (including foreknowledge of the behaviour of others) beyond the limits of an individual mind is not just solipsistic in the philosophical sense; it also removes the possibility of an explanation for social order through coordinated individual actions. If Shackle's position is indeed solipsistic, then he cannot hope to provide an account of economic coordination or social order.

I have noted in Part II that Shackle failed to systematically articulate an ontology of the objective natural realm and the intersubjective realm in which his 
agents are located (Runde 1997; Hodgson 2000). Yet few (even philosophicallyminded) economists have explicitly engaged in such ontological reflection and Shackle gives numerous glimpses of how he would analyse both natural and intersubjective phenomena. I have already discussed his account of scientific progress in Epistemics and Economics, which gives an indication of his analysis of the natural world and the sciences that describe it. Shackle delves into the intersubjective realm of shared meanings and intentions in his discussion of price formation and investment decisions. The clearest example of this is his extended analysis of Keynes' conception of convention, which suggests an acute awareness of the problems related to explaining intersubjective phenomena (Shackle 1967: 244247; Shackle 1972: 220-226). Thus the idea that Shackle's radical subjectivism leads to solipsism seems somewhat far-fetched.

Here, once again, interpreting Shackle's contribution as an EPT is helpful both to explain the critique and to suggest a response. Shackle's principled focus on individual subjectivity raises the threat of solipsism if economic agents are conceptualised as social atoms as both the language and the methods of mainstream economics presuppose (Lawson 1997). The mind of a social atom is neatly circumscribed and its objectives are determined through internal calculations. It has no perception of the passage of time and no ability to change its circumstances. For social atoms of this sort, coordination and the resulting social order are hard won achievements and radical subjectivism presents a serious threat. The existence of heterogeneous individual goals that proliferate through creative activities makes prediction through individual, rational calculation impossible and the motor force of the economy is thus broken. But Shackle never accepted this account of agency, which is articulated in the language of substance metaphysics ${ }^{9}$. His processual conception of agency is much richer. It is based on the imagination of future scenarios rather than probabilistic calculation. It is open to the influence of nonrational factors such as the news, public opinion or the prevailing social and cultural context. Perhaps most importantly, the mind of the individual chooser is not so tightly circumscribed in Shackle's work, since he conceives of the mind as a changeable flow of experiences and environmental influences rather than a static and unchanging entity.

\footnotetext{
${ }^{9}$ In the sense that it requires separate, well-defined entities, with settled identity conditions interacting in a deterministic manner to produce stable outcomes. Rescher describes the processual alternative thus: 'For processists, this processual unity of the person has a distinctly social aspect. As it sees the matter, the self-definitional activity of persons proceeds in the context of interaction with one another' (Rescher 1996: 110).
} 
The account of social order that Shackle derives from this conception of economic agency is revealed in his discussions of 'Keynesian kaleidics'. And, though much of what he says is presented as an interpretation of Keynes, there can be no doubt that Shackle adopted and developed kaleidics himself. He defines kaleidic theory as:

'... the view that the expectations, which together with the drive of needs and ambitions make up the 'springs of action', are at all times so insubstantially founded upon data and so mutably suggested by the stream of 'news', that is, of counterexpected or totally unthought-of events, that they can undergo complete transformation in an hour or even a moment, as the patterns of a kaleidoscope dissolve at a touch; the view that men are conscious of their essential and irremediable state of un-knowledge and that they usually suppress this awareness in the interest of avoiding a paralysis of action; but that from time to time they succumb to its abiding mockery and menace, and withdraw from the field.' (Shackle 1974: 42)

Shackle emphasises disorder so that he can contrast his position with the equilibrium analysis presented by his mainstream opponents. The moments of rest afforded by a temporary balance in agents' expectations, which are characteristic of the kaleidic economy, provide a glimpse of a social order in process. Even this kaleidic picture remains a mode of order; one where the impetus for both change and stability is generated within the process that produces it rather than imposed from the outside by a stable set of economic laws.

This brings us to the second perceived drawback of Shackle's framework for the analysis of social order. Whether or not his position is solipsistic, critics have objected that the kaleidic theory undermines the potential of economics as a policy science. This objection - if one is to consider it an objection at all - has considerable merit, especially when understood against the backdrop of mainstream welfare economics and its policy implications. Indeed, Shackle made his ambivalence about the potential of traditional economic policy quite clear in an interview with the Austrian Economics Newsletter in which he stated:

'I think they [economists] should give up giving advice, except on the most hesitant, the most broad grounds. I think they should introduce an ethical element, a more than ethical element. If a man is asked whether public expenditure should be cut or not, he perhaps should say, "Well, if we cut it, we shall cause a great deal of misery; if we don't cut it, we don't know what the consequences will be, but we can't at least have this misery on our consciences". This sort of argument is not an economic argument, it's an argument with one's conscience. For very many years I've not believed in welfare economics as a scientific construction. My idea of welfare 
economics is that you choose an administrator, a man with a conscience himself, and broad sympathy, with a generous mind and then you say, "Leave it to him!" I don't believe you can do any better. Those economists who are going to give advice, or who are going to be advisors either to government or to business, should have their training based in economic history, and they only need as much theory as you find up to the second year textbook.' (Shackle 1983)

Scepticism about the policy potential of economics is traditionally thought of as an admission of failure - yet another hint of underlying nihilism. And Shackle's understanding of policy-making is so entirely at odds with the mainstream perspective that it may seem to deny the possibility of social order. However, seen in the context of process theory, it is entirely justified. Note that Shackle's scepticism in the above passage is directed towards the idea that we can accurately predict future states of affairs and precisely control their development with technical interventions. He does not challenge the belief - essential to economic policy - that we have a major stake in the construction of our economic environment. Rather he denies that it can be transformed into a technical game which eschews human, moral judgments. He conceives of economic 'administrators' as sympathetic and possessing generous minds, but, most importantly, he suggests that they should be modest, cautious and well acquainted with social and economic history. This focus on history is typical of a processual perspective in that it attempts to find order in the generic structure of an unfolding process rather than the static description of states of affairs (Rescher 1996: 118-120).

\section{Conclusion}

Drawing on the philosophical literature, I have constructed a more precise and generalisable conception of economic process theory. I outlined a set of general criteria, for the identification of economic process theories and tested those criteria by applying them to a problematic case. I proposed four desiderata: an emphasis on time, the recognition of distinct phases, a commitment to process, and the accommodation of contingency, emergence and creativity. Applying this new taxonomic framework to Shackle's work, I then argued that his contribution clearly fits within the rubric of economic process theory. This conclusion is significant in that it suggests new ways to map connections between Shackle's research and that of his precursors, contemporaries and followers in other heterodox schools of thought including Austrians and old institutionalists. Finally, I argued that reading Shackle as an economic process theorist allows us to see some of the standard criticisms of his work in a new light. 
Another important objective was to demonstrate that recognising any theory as an EPT has significant methodological and theoretical consequences. In responding to the charges of nihilism, solipsism and policy ambivalence, I have illustrated this point in the context of a specific and controversial case. By drawing links between economics and process philosophy, I have also shown that processual contributions to economics should not be limited to evolutionary or Darwinian theories and that the ontology of process has a broader remit within the social sciences.

\section{$\underline{\text { References }}$}

Åkerman, J. (1958). "Professor Shackle on economic methodology". Kyklos, 11(3): 341-361.

Augier, M. (2001) "Typicality and novelty: Schütz and Shackle on the paradox of choice." The Review of Austrian Economics 14.2-3: 193-207.

Bickhard, M. H. (2003) "Process and emergence: Normative function and representation." In Process Theories: Cross-disciplinary Studies in Dynamic Categories. J. Seibt [ed.] Springer Netherlands, 121-155.

Bickhard, M. H. (2004). "The social ontology of persons." Social interaction and the development of knowledge, 111-132.

Boland, L. A. (1974). "Epistemics \& Economics: A Critique of Economic Doctrines G. L. S. Shackle." Philosophy of Science 41 (4): 424-6.

Carter, C. F., Meredith, G. P. \& Shackle G. L. S eds. (1954) Uncertainty and business decisions. Liverpool: Liverpool University Press.

Davidson, P. (1991). "Is probability theory relevant for uncertainty? A post Keynesian perspective." The Journal of Economic Perspectives, 5(1), 129-143.

Ford, J. L. (1993) "G. L. S. Shackle (1903-1992): A Life with Uncertainty." The Economic Journal. 103.418: 683-697.

Harcourt, G. C. (1981) "Notes on an economic querist: GLS Shackle." Journal of Post Keynesian Economics 4.1, 136-144. 
Harcourt, G. C., and C. Sardoni (2000) "George Shackle and Post Keynesianism." Economics as an Art of Thought: Essays in Memory of GLS Shackle 36. London: Routledge, 76-.

Hill, G. (2004) "From Hayek to Keynes: GLS Shackle and ignorance of the future." Critical Review 16.1, 53-79.

Hodgson, G. M. (2000) "Shackle and institutional economics: some bridges and barriers." Economics As an Art of Thought: Essays in Memory of GLS Shackle, 36-51.

Lachmann L. (1976) "From Mises to Shackle: An Essay on Austrian Economics and the Kaleidic Society." Journal of Economic Perspectives. 14.1: 54-62.

Lawson, T. (2006) "The nature of heterodox economics." Cambridge journal of economics 30.4, 483-505.

Lawson, T. (2012) "Ontology and the study of social reality: emergence, organisation, community, power, social relations, corporations, artefacts and money." Cambridge journal of economics 36.2, 345-385.

Lawson, T. (2014) "A Conception of Social Ontology" in S. Pratten, ed. Social Ontology and Modern Economics. London: Routledge, 19-52.

Nelson, J. A. (2003) "Confronting the science/value split: notes on feminist economics, institutionalism, pragmatism and process thought." Cambridge Journal of Economics 27.1, 49-64.

Newman G. (1974) "Book review: Epistemics \& Economics: A Critique of Economic Doctrines G. L. S. Shackle." Philosophy of the Social Sciences, 4: 409-412.

Parsons, S. D. (1993) "Shackle, nihilism, and the subject of economics." Review of Political Economy 5.2, 217-235.

Rescher, N. (1996) Process metaphysics: An introduction to process philosophy. SUNY Press.

Rescher, N. (2000) Process Philosophy: a survey of basic issues. University of Pittsburgh Press.

Runde, J. (1997) "Keynesian methodology", in A Second Edition of The General Theory, vol. 2: 222-243. London: Routledge.

Samuels, W. J. (1993) "In (limited but affirmative) defence of nihilism." Review of Political Economy 5.2: 236-244. 
Shackle, G.L.S. (1952/2012) Expectation in economics, $2^{\text {nd }}$ ed. Cambridge: Cambridge University Press.

Shackle, G.L.S. (1959) "Time and thought." The British Journal for the Philosophy of Science 9.36, 285-298.

Shackle, G.L.S. (1968) Uncertainty in Economics and other Reflections. Cambridge: CUP Archive.

Shackle, G.L.S (1972/1991) Epistemic \& economics: A critique of economic doctrines. New Brunswick (USA): Transaction Publishers.

Shackle, G. L. S. (1974). Keynesian kaleidics: the evolution of a general political economy. Edinburgh: Edinburgh University Press.

Shackle, G.L.S. (1967/1983) The years of high theory: invention and tradition in economic thought 1926-1939. Cambridge: CUP Archive.

Shackle, G.L.S (1983) "Interview with George Shackle”. Austrian Economics Newsletter: http://mises.org/journals/aen/shackle.asp [last accessed 24/09/13] Shackle, G. L. S. (1984) "Comment on the Papers by Randall Bausor and Malcolm Rutherford." Journal of Post Keynesian Economics 6.3, 388-393.

Shackle, G.L.S. (1988) Business, time, and thought: Selected papers of GLS Shackle. Ed. Stephen F. Frowen. Macmillan.

Watkins, J. W. N. (1955) "Decisions and Uncertainty." The British Journal for the Philosophy of Science 6.21, 66-78. 